\title{
A ESTATÍSTICA NO CICLO DE ALFABETIZAÇÃO: FORMAÇÃO CONTINUADA E MOBILIZAÇÃO DE CONHECIMENTOS PARA O ENSINO
}

\author{
STATISTICS IN THE LITERACY CYCLE: CONTINUED TRAINING AND \\ MOBILIZATION OF KNOWLEDGE FOR TEACHING
}

\author{
Jozeildo Kleberson Barbosa ${ }^{1}$ \\ Maria da Graca Nicoletti Mizukami ${ }^{2}$
}

\begin{abstract}
Resumo: Nesse trabalho analisamos a formação continuada oferecida pelo Pacto Nacional de Alfabetização na Idade Certa (Pnaic) e os avanços nos conhecimentos das professoras cursistas para o ensino da Estatística. Este estudo possui natureza qualitativa. Para nossa investigação realizamos a Análise Documental dos cadernos de formação do Pnaic e dos portfólios de cinco professoras que participaram do curso de formação do Pnaic em 2014, essas docentes atuavam num mesmo município. Os dados que surgiram foram confrontados e explorados com a utilização da Análise do Conteúdo. Verificamos que o Pnaic apresentou uma proposta promissora de formação para o ensino de Estatística. Nos porfólios são perceptíveis os indícios de avanços dos conhecimentos das professoras para o ensino da Estatística. Ao analisarmos o material de formação e os registros das alfabetizadoras nos portfólios observamos que a proposta do Pnaic foi bem recebida pelas docentes. Também são apresentados indícios de desenvolvimento profissional.
\end{abstract}

Palavras-chave: Formação de professores; Educação Estatística; Pacto nacional de Alfabetização na Idade Certa; Conhecimento para o Ensino; Formação Continuada.

\begin{abstract}
In this paper we analyze the continuing education offered by the National Pact of Literacy in the Right Age (Pnaic) and the advances in the knowledge of female teachers for the teaching of Statistics. This study has a qualitative nature. For our investigation we carried out the Documentary Analysis of the Pnaic training books and the portfolios of five teachers who participated in the Pnaic training course in 2014, these teachers were in the same municipality. The data that emerged was confronted and exploited with the use of Content Analysis. We verified that the Pnaic presented a promising proposal of training for the teaching of Statistics. In the porfólios the indications of advances of the knowledge of the teachers for the teaching of Statistics are perceptible. When analyzing the training materials and the records of the literacy teachers in the portfolios, we observed that the Pnaic proposal was well received by the teachers. There are also indications of professional development.
\end{abstract}

Keywords: Teacher training; Statistical Education; National Pact of Literacy in the Right Age; Knowledge for Teaching; Continuing Education.

\footnotetext{
${ }^{1}$ Doutor em Educação: Currículo pela Pontifícia Universidade Católica de São Paulo (PUC/SP). PósDoutorando no Programa Pós-Graduação em Educação, Arte e História da Cultura da Universidade Presbiteriana Mackenzie. Professor e coordenador do curso de Pedagogia EAD do Centro Universitário do Vale do Ribeira (UNIVR/Unisepe), Registro, São Paulo, Brasil. E-mail: ildojz@yahoo.com.br

${ }^{2}$ Doutora em Educação pela Pontifícia Universidade Católica do Rio de Janeiro (PUC/Rio). Professora do Programa Pós-Graduação em Educação, Arte e História da Cultura da Universidade Presbiteriana Mackenzie (UPM), São Paulo, Brasil. E-mail: gramizuka@gmail.com
} 


\section{Introdução}

Compreender as informações de gráficos, tabelas; fazer a inferência de estatísticas; saber o que é uma amostra; etc... são importantes para sermos cidadãos atuantes na Sociedade da Informação. Sua relevância é algo indiscutível em todas as áreas de conhecimento, além de que com o avanço da tecnologia e a expansão da informática as técnicas estatísticas passaram a ser mais utilizadas (BARBOSA, 2018). O ensinoaprendizagem da Estatística hoje é incorporado nos cursos de formação docente como Educação Estatística, na área da Matemática, que possui extrema relevância na sociedade moderna.

A Educação Estatística está centrada no estudo da compreensão de como as pessoas aprendem Estatística envolvendo os aspectos cognitivos e afetivos e o desenvolvimento de abordagens didáticas e de materiais de ensino (CAZORLA et al., 2017)

Assim, nosso objetivo é analisar a formação continuada oferecida pelo Pacto Nacional de Alfabetização na Idade Certa (Pnaic) e os avanços nos conhecimentos das professoras cursistas para o ensino da Estatística. Adentramos o ensino e a aprendizagem das docentes para o ensino dos conteúdos estatísticos para alunos do ciclo de alfabetização, as crianças de seis a oito anos de idade.

Defendemos ser essencial o desenvolvimento de atitudes positivas em relação à Estatística, pois todos precisam entender a sua importância como atividade humana e que sem o conhecimento estatístico podemos ser induzidos a erros de julgamento, pela manipulação de dados e pela apresentação incorreta das informações (CAZORLA, 2004), ou seja, proporciona uma educação para cidadania (D’AMBROSIO, 1996).

Este estudo possui natureza qualitativa. Para nossa investigação realizamos a Análise Documental dos cadernos de formação do Pnaic e dos portfólios de cinco professoras que participaram do curso de formação do Pnaic em 2014, essas docentes atuavam num mesmo município. Os dados que surgiram foram confrontados e explorados com a utilização da Análise do Conteúdo.

O presente artigo é uma ramificação de um estudo amplo desenvolvido no âmbito de uma investigação em nível de pós-doutorado do primeiro autor, sendo supervisionado pela segunda autora, relativo a formação de professoras alfabetizadoras no Pnaic. 


\title{
2 Formação continuada para alfabetizadoras e o ensino de Estatística
}

O Pnaic, instituído pela Portaria nº 867/2012 (BRASIL, 2012), é concebido como um compromisso formal assumido pelo Governo Federal, o Distrito Federal, os estados e municípios para assegurar que todas as crianças estejam alfabetizadas até os oito anos de idade, ou seja, ao final do $3^{\circ}$ ano do Ensino Fundamental. Para cumprir seu objetivo o programa congrega políticas públicas nacionais voltadas à Educação Básica, além de ser o maior programa de formação já implementado pelo Ministério da Educação (MEC).

As ações do programa se apoiaram em quatro eixos de atuação: Formação continuada presencial para as professoras; Materiais didáticos, obras literárias e de apoio pedagógico, jogos e tecnologias educacionais; Avaliações sistemáticas; e Gestão, mobilização e controle social. A formação oferecida foi um curso presencial para as cursistas, denominadas professoras alfabetizadoras (PAs). Inicialmente o programa teria dois anos de duração, foi ampliado para três, posteriormente para quatro e recentemente completou o sexto ciclo da formação.

Freire (1996) nos adverte sobre a necessidade de formação continuada para os docentes:

\begin{abstract}
A responsabilidade ética, política e profissional do ensinante lhe coloca o dever de se preparar, de se capacitar, de se formar antes mesmo de iniciar sua atividade docente. Esta atividade exige que sua preparação, sua capacitação, sua formação se tornem processos permanentes. Sua experiência docente, se bem percebida e bem vivida, vai deixando claro que ela requer formação permanente do ensinante. Formação que se funda na análise critica de sua prática (p. 28).
\end{abstract}

Para o autor, ser professor é estar em um processo continuo de formação, de aquisição de conhecimentos para o ensino.

A cada ano os cursos de formação giraram em torno de eixos temáticos: 2013: Alfabetização e Letramento, 2014: Ensino de Matemática, 2015: Interdisciplinaridade, 2016: Avaliações, 2017/2018: Alfabetização como direito. Entretanto, as discussões não se limitaram a esses temas. No Pnaic deveriam ser desenvolvidas ações que visassem contribuir acerca dos direitos de aprendizagem ${ }^{3}$ (BRASIL, 2012) das crianças do ciclo de alfabetização; para os processos de avaliação e acompanhamento da aprendizagem das crianças; para o planejamento e avaliação das situações didáticas; para o conhecimento e

\footnotetext{
3 Para mais informações, acesse o documento "Direitos de Aprendizagem". Disponível em: http://portal.mec.gov.br/index.php?option=com_docman\&view=download\&alias=12827-textoreferencia-consulta-publica-2013-cne-pdf\&category_slug=marco-2013-pdf\&Itemid=30192. Acesso em: 15 abr. 2019.
} 


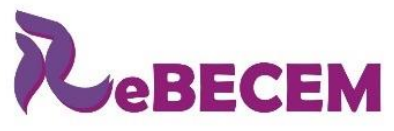

DOI: http://dx.doi.org/10.33238/ReBECEM.2019.v.3.n.2.22607
Revista Brasileira de Educação em

Ciências e Educação Matemática

ISSN 2594-9179

uso dos materiais distribuídos pelo MEC, voltados para a melhoria da qualidade do ensino do $1^{\mathrm{o}}$ ao $3^{\circ}$ ano do ensino fundamental.

Para o curso de formação foram elaborados pelas Universidades que aderiram às ações do Pnaic cadernos de formação que deveriam pautar os conteúdos e temáticas dos encontros presenciais entre as formamadoras, Orientadoras de Estudo (OE), e as cursistas, Professoras Alfabetizadoras (PA), como foram nomeados os principais papéis das ações do programa.

Ao falar em educação para cidadania, D’Ambrosio (1996, p. 87), frisa que essa “é um dos grandes objetivos da educação de hoje, exige uma 'apreciação' do conhecimento moderno, impregnado de ciência e tecnologia". Consideramos que a Educação Estatística dos alunos possui forte ligação com essa educação para cidadania, permitindo aos jovens cidadãos transitar com mais facilidade nessa Sociedade da Informação.

Segundo Cazorla et al., (2017) a Educação Estatística tem como foco a compreensão de como as pessoas aprendem Estatística e envolve os aspectos cognitivos, afetivos e o desenvolvimento de abordagens didáticas e de materiais de ensino. Devido a tal dimensão, congrega a Educação Matemática, a Psicologia, a Pedagogia, a Filosofia, a Matemática, além da própria Estatística. Ademais, o pensamento estatístico pode ser "definido como a capacidade de utilizar e/ou interpretar, de forma adequada, as ferramentas estatísticas na solução de problemas" (p. 15). Para autora, isto "envolve o entendimento da essência dos dados e da possibilidade de fazer inferências, assim como o reconhecimento e a compreensão do valor da Estatística como uma disposição para pensar numa perspectiva da incerteza". (p. 15)

Sobre o ensino de Estatística, Cazorla (2004) afirma que:

\begin{abstract}
A Educação Estatística no Brasil tem seu marco histórico na Conferência Internacional "Experiências e Expectativas do Ensino de Estatística - Desafios para o Século XXI", realizado na Universidade Federal de Santa Catarina (UFSC, 1999) e começa a tomar forma, enquanto área de pesquisa, com tendência crescente e perspectivas de consolidação ( $\mathrm{s} / \mathrm{n})$.
\end{abstract}

Para a autora, no Brasil a oficialização do ensino da Estatística na Educação Básica foi com o lançamento dos Parâmetros Curriculares Nacionais (PCNs) e até aquele momento os conhecimentos estatísticos eram abordados no final do livro-texto / livro didatico, ou seja, quase nunca eram ensinados por falta de tempo.

Lopes (2008) afirma que as propostas curriculares para a área de Matemática têm procurado justificar a importância e a relevância da Estatística na formação dos alunos, pois “torna-se indispensável ao cidadão nos dias de hoje e em tempos futuros, delegando 
DOI: http://dx.doi.org/10.33238/ReBECEM.2019.v.3.n.2.22607

ao ensino da Matemática o compromisso de não só ensinar o domínio dos números, mas também a organização de dados, leitura de gráficos e análises estatísticas” (p. 58). Nesse sentido é preciso:

O repensar do papel do professor no processo do ensinar e do aprender tem estado na pauta nacional de educação e tem sido foco central de algumas políticas públicas. No entanto, ainda não se podem perceber resultados significativos no que se refere à formação estocástica dos alunos que têm finalizado o ensino médio (LOPES, 2008, p. 64).

Sendo o Pnaic um programa que tem maior foco na formação continuada, concordamos com a Unesco (2016) que ao tratar do desafio da evolução das práticas de ensino; por com muita frequência a Matemática na Educação Básica ser apresentada aos alunos de forma pouco estimulante:

\begin{abstract}
- Concebido como um ensino formal, centrado na aprendizagem de técnicas e na memorização de regras, cujo significado não é destacado para os estudantes. - No ensino, os objetos matemáticos são introduzidos sem que se conheçam as necessidades a que devem responder, tampouco se comentam suas articulações com os objetos precedentes. - Dentro dele, as relações com o mundo real são tênues, geralmente muito artificiais para serem convincentes, e as aplicações são estereotipadas. - Dentro dele, as práticas experimentais e as atividades de modelagem são raras. - Dentro dele, uma utilização pertinente da tecnologia ainda permanece relativamente rara. - Nele, os estudantes têm pouca autonomia no seu trabalho com a matemática e são frequentemente limitados nas tarefas de reprodução (p. 21).
\end{abstract}

Nesse contexto, Mizukami et al., (2010) nos mostra que a formação continuada busca novos caminhos de desenvolvimento, "deixando de ser reciclagem, como preconizava o modelo clássico, para tratar de problemas educacionais, por meio de um trabalho de reflexividade crítica sobre as práticas pedagógicas e de uma permanente (re)construção da identidade docente" (p. 28).

Um programa de formação continuada deve ir além de suprir conhecimentos que deveriam ter sido consolidados na formação inicial, deve oportunizar aos docentes se desenvolver como profissionais do ensino, avançando em várias vertentes do conhecimento base para o ensino (SHULMAN, 1986, 1987). Defendemos o aprofundamento dos conhecimentos estatísticos e do seu ensino para as professora que atuam no ciclo de alfabetização por termos consciência que, geralmente, essas docentes possuem lacunas em seu conhecimento, tanto de conteúdo, como pedagógico e do currículo referente à Estatística na Educação Básica.

Cazorla (2004) ao analisar o currículo de cursos de Pedagogia, que forma os professores dos anos inicais do Ensino Fundamental, assevera:

Analisando a grade curricular desses cursos observa-se que a maioria dos cursos oferece uma disciplina de Estatística, outros, duas, e alguns, nenhuma 
DOI: http://dx.doi.org/10.33238/ReBECEM.2019.v.3.n.2.22607

(Gonçalves, 2003). Duas disciplinas aparecem ligadas a estes cursos:

Estatística Educacional (indicadores educacionais) e Estatística Aplicada à Educação, enquanto ferramenta de tratamento de dados e noções de inferência estatística. Observa-se que nenhuma dessas disciplinas contempla a Didática da Estatística, o que também não fica explicito na disciplina de Metodologia de Ensino da Matemática. Observa-se, ainda, que os alunos dos cursos de Pedagogia mostram resistência à Matemática e Estatística, em alguns cursos as disciplinas de Estatística foram extintas. Estes profissionais são os professores que lecionam a disciplina de Matemática e, consequentemente, os conteúdos de Estatística e Probabilidades para as crianças (s/n).

Algo também encontrado por Curi (2004) em sua pesquisa sobre os conhecimentos para ensinar Matemática e das crenças e atitudes que interferem na constituição desses conhecimentos. A autora, ao analisar ementas, observou que $50 \%$ dos cursos de Pedagogia analisados apresentavam a Estatística; entretanto seu foco estava no estudo dos conceitos básicos da estatística descritiva, "como a organização de dados, técnicas de amostragem, medidas de tendência central e medidas de dispersão. Mas essa disciplina também é considerada como uma ferramenta auxiliar para dinâmica do fluxo escolar e para análise dos problemas brasileiros" (p. 69).

Batanero e Diaz (2010) e Kataoka et al., (2011) também corroboram essas dificuldades das alfabetizadoras para ensinar Estatística no Ensino Fundamental ao não encontrarem em suas pesquisas uma discussão na formação inicial de professores a respeito de questões relacionadas à didática da Estatística. Observa-se que o Pnaic ao abordar a Educação Estatística possibilita que as docentes possam avançar em seu conhecimento para o ensino (SHULMAN, 1986, 1987), principalmente por que "muitos professores inconscientemente compartilham uma variedade de dificuldades e equívocos com seus alunos relacionados a ideias estatísticas fundamentais" (BATANERO; BURRIL; READING, 2011, p. 409).

Lopes (2008) assevera que o elemento central do conhecimento profissional do professor é o conhecimento pedagógico do conteúdo, mas este por si só não é suficiente. "Faz-se necessária uma combinação adequada entre o conhecimento sobre o conteúdo matemático a ser ensinado e o conhecimento pedagógico e didático de como ensiná-lo" (p. 66). Para a especialista:

O conhecimento didático do conteúdo é uma síntese entre os conteúdos a ensinar e os modos de fazê-lo, incluindo formas de representação das ideias, analogias importantes, ilustrações e exemplos próximos ao contexto. Está incorporada a esse conhecimento a habilidade em representar e formular o conteúdo conceitual e/ou procedimental, tornando-o compreensível aos alunos, gerando a compreensão do que torna a aprendizagem de um conceito mais ou menos difícil e de suas respectivas concepções (LOPES, 2008, p. 66). 
DOI: http://dx.doi.org/10.33238/ReBECEM.2019.v.3.n.2.22607

É concenso entre as classificações para a base de conhecimento dos professores que o conhecimento de como ensinar os conteúdos é o de maior relevância. Shulman (1986) o classifica como conhecimento pedagógico do conteúdo e é uma combinação entre o conhecimento da matéria/área e o modo de ensiná-la, que, segundo o autor:

[...] incorpora os aspectos do conteúdo mais relevantes para serem ensinados. Dentro da categoria de conhecimento de conteúdo pedagógico, incluo, para a maioria dos tópicos regularmente ensinados de uma área específica de conhecimento, as representações mais úteis de tais ideias, as analogias mais poderosas, ilustrações, exemplos, [...] as concepções e preconcepções que estudantes de diferentes idades e repertórios trazem para as situações de aprendizagem ( p. 9).

Para o especialista, esse é o conhecimento onde o professor é o verdadeiro protagonista. A esse respeito Batanero (2002), descreve os componentes básicos do que considera o "Conhecimento Pedagógico da Estatística":

\begin{abstract}
- A reflexão epistemológica sobre o significado de conceitos, procedimentos (geralmente objetos) tem como objetivo ensinar os indivíduos, ou seja, neste caso, a reflexão epistemológica sobre a natureza do conhecimento estocástico, o seu desenvolvimento e evolução. - Análise das transformações do conhecimento para se adaptar a diferentes níveis de ensino. Esta análise permite refletir sobre os diversos níveis possíveis de compreensão sobre o mesmo conhecimento e avaliar o nível e, particularmente, como um conceito particular poderia ser ensinado a uma pessoa em particular. - Estudo sobre as dificuldades, os obstáculos e os erros dos alunos na aprendizagem e estratégias de resolução de problemas que irão orientar melhor o trabalho de ensino e avaliação de aprendizagem. - Análise de currículo, ensinando situações, ensinando metodologia para temas específicos e recursos pedagógicos específicos. Isso faz parte dos recursos metodológicos para melhorar a ação educativa (p. 95)
\end{abstract}

Realizando nossa análise com base nas concepções de Shulman (1986, 1987) temos uma concepção semelhante a Lopes (2008) e Batanero (2002) e defendemos que num processo de formação continuada deve haver um equilibração entre conhecimento do conteúdo, conhecimento pedagógico do conteúdo e conhecimento do currículo, sendo esse um tripé de sustentação para o desenvolvimento profissional docente em processos de formação continuada.

Evidenciasse que o Pnaic ao buscar fomentar a formação pedagógica das alfabetizadoras para o ensino de Estatística é uma proposição promissora para superar os problemas apresentados e para melhoria das práticas de ensino no ciclo de alfabetização, do $1^{\circ}$ ao $3^{\circ}$ ano do Ensino Fundamental.

No material produzido para a formação no ano de 2014 a Educação Estatística é abordada no sétimo caderno de formação. No curso de formação houve apenas um encontro com essa temática, englobando todo o eixo Tratamento da Informação. Passamos a analisar o caderno de formação Educação Estatística (BRASIL, 2014). 


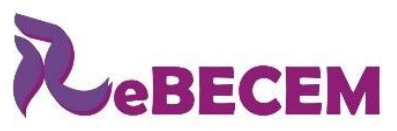

\section{0 material de formação do Pnaic}

O ensino de Estatística esteve por muito tempo ausente do currículo escolar e, consequentemente, da formação dos professores. Barbosa (2014) ao tratar do ensino e avaliação do eixo Tratamento da Informação, destaca que podemos:

[...] analisar que o ensino de Tratamento da Informação, tanto ao que se refere às praticas dos professores como aos materiais produzidos para o ensino, ainda está distante das prescrições curriculares, não recebendo a devida atenção ou investimento pedagógico necessário aos conteúdos desse tema (p. 58).

O que ressalta a importância da inclusão da Educação Estatística como temática do Pnaic. Destarte, não se pode negar que a enfaze em tais conteúdos na escola ou nas políticas públicas de formação inicial e contínua de professores ainda é abaixo do necessário.

A Educação Estatística é abordada no sétimo caderno, onde é explorado o eixo Tratamento da Informação. As reflexões presentes nos textos envolvem a pesquisa, a classificação e categorização, a construção e interpretação de gráficos e tabelas, o ensino de combinatória no ciclo de alfabetização e a abordagem da probabilidade nos primeiros anos escolares. Uma breve análise do caderno é apresentada no Quadro 1.

Quadro 1: Caderno 7 - Educação Estatística

\begin{tabular}{|c|c|c|}
\hline CADERNO & TEMÁTICA/CONTEÚDOS & OBJETIVOS \\
\hline $\begin{array}{l}\text { Educação } \\
\text { Estatística }\end{array}$ & $\begin{array}{l}\text { - Educação Estatística e pesquisa } \\
\text { - Classificação e Categorização } \\
\text { - Construção e interpretação de gráficos e } \\
\text { tabelas } \\
\text { - O ensino de combinatória no ciclo de } \\
\text { alfabetização } \\
\text { - Probabilidade nos primeiros anos escolares }\end{array}$ & $\begin{array}{l}\text { - Apresentar a Educação } \\
\text { Estatística, fornecendo ao } \\
\text { professor elementos que } \\
\text { permitam o planejamento de } \\
\text { práticas pedagógicas que } \\
\text { auxiliem a criança a reconhecer } \\
\text { e produzir informações, em } \\
\text { diversas situações e diferentes } \\
\text { configurações. }\end{array}$ \\
\hline
\end{tabular}

Fonte: Elaborado pelo autor

De acordo com o Pnaic:

Com o conteúdo deste Caderno busca-se inserir a criança no universo da investigação, a partir de situações de interesse próprio, realizando coletas de dados e apresentando-os em gráficos e tabelas. Gráficos e tabelas, além de serem ferramentas para apresentação de dados, são recursos para a elaboração de problematizações relativas a outros eixos dos Direitos de Aprendizagem (BRASIL, 2014, p. 05).

No material é fomentada a atitude investigativa - formular questões, elaborar hipóteses, escolher amostra e instrumentos adequados - para a resolução de problemas; para isso a coleta, classificação e representação dos dados é fundamental para a tomada 
DOI: http://dx.doi.org/10.33238/ReBECEM.2019.v.3.n.2.22607

de decisão. Destarte, a pesquisa é posta como o eixo principal da formação estatística dos alunos de todos os níveis de ensino.

Os textos teóricos apresentados no caderno (“A pesquisa como eixo estruturador da Educação Estatística", "Classificação e Categoria", "Construção e interpretação de gráficos e tabelas", "O ensino de combinatória no ciclo de alfabetização" e "Probabilidade nos primeiros anos escolares") foram elaborados por especialistas com grande experiência na área. Ressaltando-se que cada caderno de formação foi analisado por equipes de consultores, pareceristas ad hoc e leitores críticos.

As discussões propostas buscam temáticas do cotidiano o que auxilia a compreensão dos temas envolvidos. Lopes (2008) afirma que para consolidar o ensino da Estatística é importante que se possibilite aos alunos o confronto com problemas variados do mundo real e que tenham possibilidades de escolherem suas próprias estratégias para solucioná-los. Para autora:

Acreditamos ser necessário que nós, professores, os incentivemos a
socializarem suas diferenciadas soluções, aprendendo a ouvir críticas, a
valorizar seus próprios trabalhos e os dos outros. Nesse contexto, o trabalho
com esses temas pode ser de grande contribuição, tendo em vista sua natureza
problematizadora que viabiliza o enriquecimento do processo reflexivo
(LOPES, 2008, p. 61).

Nos anos iniciais já está presente a necessidade de desenvolver a contagem de possibilidades, a combinatória; dessa forma, a partir de estratégias das próprias crianças é possível introduzir formas variadas de organizar os dados, como, por exemplo, as tabelas de dupla entrada. Em relação ao raciocínio probabilístico, mesmo embora no ciclo de alfabetização não precise ser sistematizado, pode ser iniciado a partir de situações lúdicas desenvolvendo conceitos simples, auxiliando a criança a identificar eventos com maior ou menor chance de ocorrer.

Batanero, Burril e Reading (2011) ao analisar as pesquisas sobre o "Conhecimento Pedagógico da Estatística", afirmam haver uma escassez de estudos e sugerem que o conhecimento requerido para o ensino é, muitas vezes, fraco e gerando insegurança e limitações ao professor.

È esperado que as docentes, após realizassem a exploração do caderno de formação, desenvolvessem/incorporassem práticas pedagógicas voltadas à:

[...] ler, interpretar e fazer uso das informações expressas na forma de ícones, símbolos, signos e códigos em diversas situações e em diferentes configurações (anúncios, gráficos, tabelas, rótulos, propagandas), para a compreensão de fenômenos e práticas sociais; formular questões que gerem pesquisas e observações para coletar dados quantitativos e qualitativos; coletar, organizar e construir representações próprias para a comunicação de dados 
DOI: http://dx.doi.org/10.33238/ReBECEM.2019.v.3.n.2.22607

coletados (com ou sem o uso de materiais manipuláveis ou de desenhos); ler e interpretar listas, tabelas simples, tabelas de dupla entrada, gráficos; elaborar listas, tabelas simples, tabelas de dupla entrada, gráfico de barras e pictóricos para comunicar a informação obtida, identificando diferentes categorias; produzir textos a partir da interpretação de gráficos e tabelas; problematizar e resolver situações a partir das informações contidas em tabelas e gráficos; reconhecer e diferenciar situações determinísticas e probabilísticas; identificar a maior ou menor chance de um evento ocorrer (BRASIL, 2014, p. 5-6).

Segundo o programa é importante sublinhar que a Educação Estatística vai ocorrer em duplo contexto, da alfabetização matemática e do letramento em língua portuguesa.

As discussões propostas são propícias para a mobilização do conhecimento pedagógico do conteúdo, conhecimento do currículo e conhecimento do conteúdo. Sobre o conhecimento do conteúdo, por exemplo, é favorável a proposição de reflexão sobre população, amostra, levantamento de dados, classificação e categorização conhecimentos ligados ao campo da Estatística.

Cazorla et al., (2017) apresenta algumas constatações sobre a necessidade de materiais de formação/apoio aos docentes:

[...] a constatação da pouca disponibilidade de material de apoio para auxiliar os professores no ensino dos conceitos elementares da Estatística, principalmente voltados para os anos iniciais do Ensino Fundamental. [...] a necessidade de tratarmos a Educação Estatística considerando tanto a formação para a cidadania como para o desenvolvimento do pensamento científico. De fato, saber ler e interpretar informações estatísticas permite ao indivíduo entender, avaliar e se posicionar frente a informações veiculadas costumeiramente na mídia, as quais, muitas vezes, têm influência nos rumos políticos e econômicos da sociedade. Contudo, também é preciso auxiliar o indivíduo no desenvolvimento do pensamento científico. Propiciar situações para que ele saiba, por exemplo, identificar um problema, elaborar questões, levantar hipóteses e testar sua validade, isto é, saber escolher os dados a serem coletados, organizá-los e interpretá-los. [...] oferecer um produto de qualidade, escrito com uma linguagem acessível a todos os educadores e, ainda, disponibilizar para o professor exemplos voltados para a prática docente, por meio dos quais ele possa se sentir mais confortável para abordar as ideias básicas e essenciais da Estatística em sua sala de aula (p. 11-12).

Durante os textos são analisadas várias atividades de alunos, o que favorece a reflexão sobre o ensino. Alguns experimentos são sugeridos. Na seção "Compartilhando" existem atividades para aplicação na sala de aula. Mizukami e Reali (2002), salienta que "[...] quando os professores descrevem, analisam e fazem inferências sobre eventos em sala de aula, eles estabelecem seus próprios princípios pedagógicos. A reflexão oferecelhes a oportunidade de objetivar suas teorias práticas/implícitas" (p. 49).

Ao final do material estão sugestões de leituras, de vídeos, de sites e jogos online, também há sugestões de atividades para os encontros em grupos e atividades para casa e escola.

Freire (1989) assevera que precisamos de professores: 
DOI: http://dx.doi.org/10.33238/ReBECEM.2019.v.3.n.2.22607

[...] que valorizem a unidade teoria e prática, professores curiosos que respeitem a linguagem da criança, que pensem rigorasamente sem abandonar a poesia, que proponham uma forma científica de pensar o mundo, sendo assim capazes de fazer uma reflexão crítica sobre sua própria prática (p. 5)

Assim, os materiais de formação são fontes importante para que os professores se aproximem da teoria e a transpussessem para a prática, para isso a atuação das orientadoras de estudo era fundamental. Passamos a presentar os registro nos portfólios do encontro de formação.

\section{$4 O$ encontro de formação na voz das PAs}

Não se pode negar que a formação continuada tem por objetivo que os professores avancem em seus conhecimentos. Shulman $(1986,1987)$ considera o conhecimento do conteúdo de uma forma particular diante da reflexão sobre a formação de professores. Pesquisas que se desenvolveram com as ideias do autor, tal como a de Ball, Thames e Phelps (2008) indicam que o professor que ensina Matemática não deve saber apenas o conteúdo; é fundamental que o docente em sua formação estude os conteúdos que serão ensinados na escola com um olhar voltado para o ensino - produzindo conhecimento pedagógico - e não simplesmente para aquisição de conhecimento. Para Shulman (1987) "o teste definitivo para confirmar a compreensão de um assunto é a capacidade para o ensinar, transformando o conhecimento em ensino". (p.14).

A formação de Educação Estatística realizada, a sétima unidade do ciclo de formação em 2014, foi abordada em 08 de novembro de 2014 e teve dois objetivos, fornecer às professoras elementos que permitissem o planejamento de práticas pedagógicas que auxiliassem a criança a ser inserida no universo da investigação, a reconhecer e produzir informações, a desenvolver a contagem de possibilidades e o raciocínio combinatório, e; discutir o papel investigativo que se coloca no trabalho com problemas.

$\mathrm{O}$ encontro de formação teve como atividade de deleite a leitura do livro "Apostando com o monstro"4 Kyoung Hwa de Kim e Chul Yoon Jung. O livro conta a história de um monstro que adorava ganhar apostas, até que um menino muito esperto se muda para a aldeia e tira o sossego do monstro. O enredo da história apresenta a

\footnotetext{
${ }^{4}$ KIM, K. H.; JUNG, C. Y. Apostando com o Monstro. 1. ed. São Paulo: Callis Editora. 2009. O livro apresenta a comparação de quantidades entre diferentes conjuntos e a relação de grandeza dos números. Conta a história de um monstro que adorava ganhar apostas. Até o dia em que um menino muito esperto se muda para a aldeia e tira o sossego do monstro.
} 
DOI: http://dx.doi.org/10.33238/ReBECEM.2019.v.3.n.2.22607

comparação de quantidades entre diferentes conjuntos e a relação de grandeza entre números.

Segundo a pauta do encontro, houve a retomada do encontro anterior, atividade onde foram retomadas situações do oitavo encontro e a entrega de tarefas. Também foi abordada a Provinha Brasil ${ }^{5}$ e seus descritores e o que são distratores. Assim como os direitos de aprendizagem no eixo Tratamento da Informação.

Em seguida foi realizado o estudo coletivo de três textos, "Pesquisa como eixo estruturador da abordagem de ensino da estatística", "Classificação e Categorização" como apoio a esse texto foi utilizado o jogo de classificação - quarta atividade do caderno de formação (BRASIL, 2014), “Construção e interpretação de gráficos e tabelas” - como apoio foram analisadas algumas atividades de livros didáticos.

$\mathrm{Na}$ atividade de estudo coletivo as alfabetizadoras se dividiram em grupos; leram e discutiram o conteúdo de cada texto e depois foi realizado um momento de socialização. Durante esse estudo coletivo foi fomentada pela OE a reflexão sobre práticas já desenvolvidas pelas PAs. Terminado o momento de socialização, houve a parada para o almoço.

Após o horário de intervalo, o encontro foi retomado e como leitura deleite foi

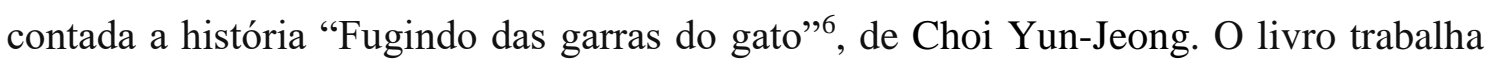
com a representação visual e gráfica de quantidades, através da história de um grupo de ratinhos que precisa amarrar algo barulhento no pescoço de um gato malvado para fugir de suas garras. Para tomar cada decisão, os ratos faziam uma votação. As docentes analisaram as possibilidades pedagógicas desse livro em relação à Educação Estatística.

No segundo momento de estudo coletivo foram abordados os textos " $\mathrm{O}$ ensino de combinatória no ciclo de alfabetização" e "Probabilidade nos primeiros anos escolares". No primeiro foi realizada a análise das resoluções utilizadas pelas crianças, já no segundo, a reflexão sobre probabilidade através de jogos. Após a análise em grupo, foi feita a socialização das reflexões de cada grupo.

\footnotetext{
${ }^{5}$ É uma avaliação diagnóstica que visa investigar as habilidades desenvolvidas pelas crianças matriculadas no $2^{\circ}$ ano do ensino fundamental das escolas públicas brasileiras. Composta por testes de Língua Portuguesa e Matemática, permite obter informações que auxiliem o monitoramento e a avaliação dos processos de desenvolvimento da alfabetização e do letramento inicial e das habilidades iniciais em matemática.

${ }^{6}$ YUN-JEONG, C. Fugindo das Garras do Gato. 2. ed. São Paulo: Callis Editora, 2008. O livro trabalha com a representação visual e gráfica de quantidades, através da história de um grupo de ratinhos que precisa amarrar algo barulhento no pescoço de um gato malvado, para fugir de suas garras. Para tomar cada decisão, fazem uma votação!
} 
DOI: http://dx.doi.org/10.33238/ReBECEM.2019.v.3.n.2.22607

Logo após, foi realizada a atividade de avaliação/fechamento do encontro, onde as docentes destacaram o que consideraram importante para o seu trabalho em relação aos conteúdos teóricos e práticos desenvolvidos nessa unidade; dando alguns exemplos e escrevendo sobre a importância desse conhecimento para a sua prática pedagógica.

Posteriormente, foi passada a tarefa de casa/escola, onde cada professora deveria desenvolver em sua turma um dos jogos vivenciados durante o encontro ou uma sequência didática que permitisse aos alunos planejar uma investigação/pesquisa estatística. A entrega dessa atividade ficou estabelecida para o encontro seguinte.

No quadro 2 apresentamos a pauta do encontro.

Quadro 2: Unidade 7 - Educação Estatística Unidade 7 - Educação Estatística

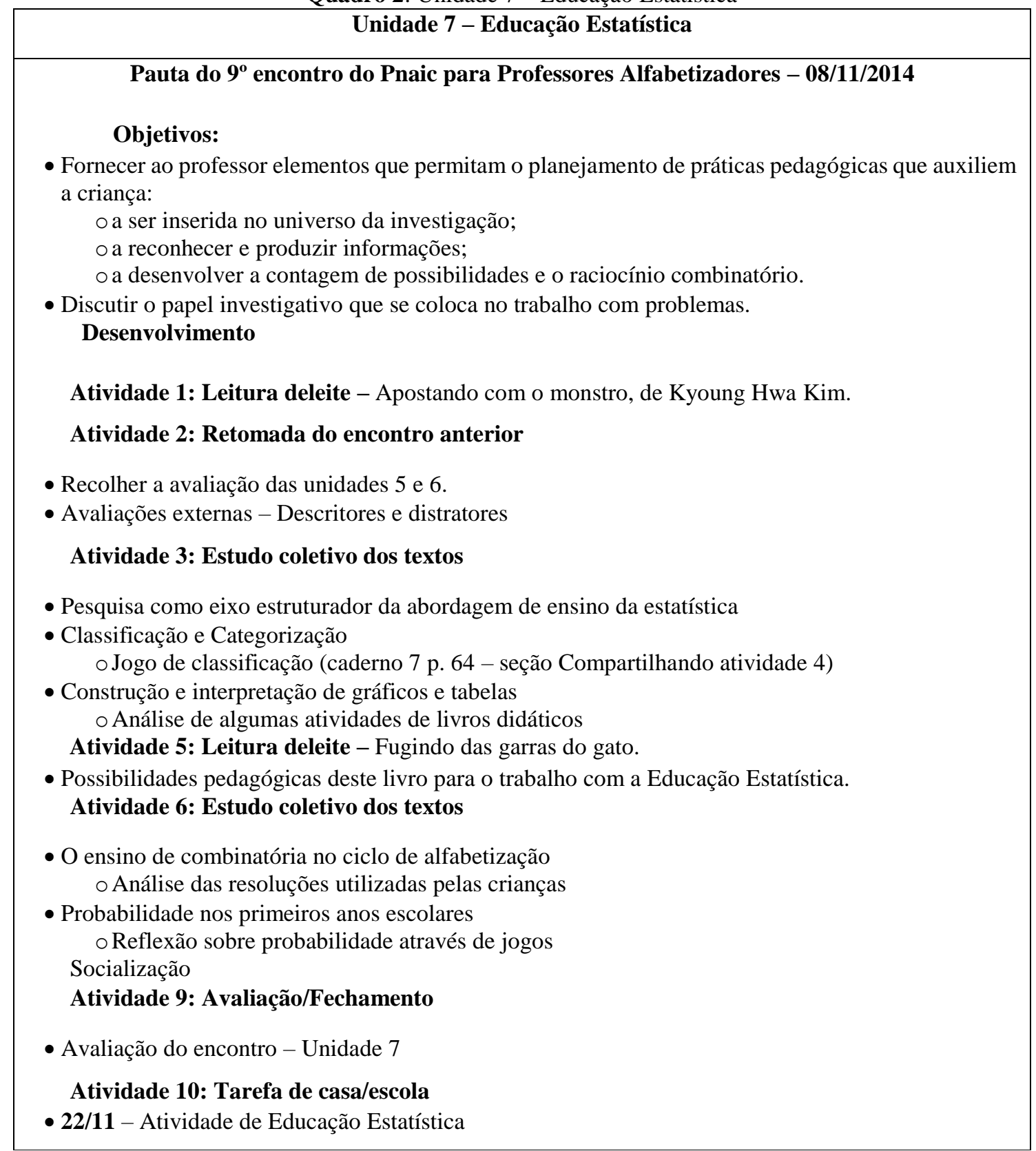

Fonte: Adaptado pelo autor da pauta original do encontro 
DOI: http://dx.doi.org/10.33238/ReBECEM.2019.v.3.n.2.22607

O encontro de formação sobre a Educação Estatística possui uma estrutura semelhante aos demais momentos da formação do ano de 2014. Seu objetivo era proporcionar às professoras o planejamento de práticas pedagógicas que auxiliassem as crianças a se alfabetizar nos conhecimentos estatísticos.

Por meio de discussões de textos sobre a Educação Estatística se buscou auxiliar as docentes a refletir sobre a organização do trabalho pedagógico e a desenvolver uma atividade em sala de aula. Como elementos formativos foram fomentados a troca de experiências e a mobilização e construção coletiva do saber docente.

O conteúdo dos portfólios é apresentado a seguir.

Sobre o encontro de Educação Estatística, a PA1 ressalta que " $O$ trabalho realizado trouxe bons resultados possibilitando proporcionar aos alunos situaçõesproblema contextualizando experiências e conhecimentos de práticas sociais de leitura e escrita” (PA1). Em sua avaliação essa unidade possibilitou avanços nas suas práticas pedagógicas com as crianças. A alfabetizadora reflete que:

Estamos na Era da Informação, as informações nos chegam o tempo todo e torna-se cada vez mais precoce o acesso do cidadão a questões sociais $e$ econômicas com gráficos e tabelas e fica muito claro que não basta ao cidadão entender de porcentagens, números, ele precisa entender relacionar e analisar criticamente os dados estatísticos que lhe são apresentados todos os dias. A matemática e a estatística são ferramentas importantes, a apropriação dos seus conceitos contribui muito para a formação do cidadão. É fundamental para o mundo do trabalho o aluno saber comunicar suas idéias, esses conteúdos visam desenvolver as habilidades necessárias e criam possibilidades de capacidade critica e a autonomia de êxito na vida profissional. Os professores e alunos devem aceitar o papel de participantes no processo ensino aprendizagem na construção desses conhecimentos (PA1).

Em sua reflexão a PA defende os princípios presentes no caderno de formação e ressalta a importância do uso social dos dados estatísticos. Cita a necessidade de relacionar e analisar criticamente dos dados estatísticos e para a formação visando a cidadania; saber comunicar ideias, formação de habilidades e capacidade crítica e a autonomia. Percebe-se que a docente incorporou os aspectos pedagógicos trazidos pelo material de formação do programa.

$\mathrm{Na}$ atividade que deveria aplicar em sua turma de alunos na tarefa de casa/escola, o jogo "Pintando o sete", a professora salienta sua intervenção junto aos alunos e suas observações:

No decorrer do jogo fui questionando em relação quem fez mais ou menos pontos, quantos pontos faltam para tal criança ganhar o jogo e assim por diante. Pude observar que os alunos participaram com entusiasmo e atenção isso significa que compreenderam a regra do jogo (PA1). 
DOI: http://dx.doi.org/10.33238/ReBECEM.2019.v.3.n.2.22607

Os jogos tiveram um papel significativo para o processo formativo das PAs no Pnaic; seja para vivênciar entre as cursistas possíveis dificuldades das crianças ou para aplicar em suas salas de aula e refletir sobre a prática, esse recurso pedagógico possibilitou intervenções mais apuradas nas dificuldades dos alunos e a participação ativa das PAs.

Sobre a importância desse eixo, a PA2 afirmou: “Observei e notei a importância do conteúdo da educação estatística, bem como a pesquisa de eixo estruturador, o valor dos dados obtidos pelos alunos durante a pesquisa de gráficos e tabelas” (PA2). A leitura deleite também foi um fator que foi ressaltado por essa docente, "O encontro teve início com a leitura deleite: Apostando com os monstros, uma leitura que fornece oportunidade para o trabalho de diversos conteúdos" (PA2).

Cazorla e Santana (2006) ao fazerem uma revisão das grades curriculares dos cursos de Pedagogia verificam que "analisando as ementas dessas disciplinas, constatase que o tempo é exíguo para dar conta dos conteúdos e métodos da Matemática e Geometria, e mais recentemente, da Estatística e Probabilidades" (p. 03). As pesquisadoras indicam uma lacuna formativa do curso que prepara as professoras alfabetizadoras, o que justifica, em parte, a inclusão da Educação Estatística no Pnaic e a receptividade das PAs em relação às propostas apresentadas no encontro de formação.

$\mathrm{Na}$ tarefa de casa/escola, a PA apresentou a atividade de Educação Estatística realizada:

\begin{abstract}
$1^{a}$ Atividade: Elaborando Coleta de dados. Para iniciar, realizei a leitura de um texto com o título, "O nosso maior presente”. Após a leitura iniciamos uma conversa sobre presente de Natal. Cada aluno expôs sua opinião, na lousa fui escrevendo uma lista com os nomes dos presentes, solicitado pelos alunos. Despertei na sala a curiosidade de conhecer a opinião das outras crianças. Então vamos realizar uma pesquisa para sabermos qual presente de natal, os alunos dos $1^{\circ}$ anos gostariam de ganhar. Providenciei uma cédula de votação, para fazer a pesquisa. Separei a turma em 3 grupos com 5 crianças em cada grupo, cada grupo ficou responsável por uma sala $\left(1^{\circ} \mathrm{A}, 1^{\circ} \mathrm{B}, 1^{\circ} \mathrm{C}\right)$ para realizar a coleta de dados. $2^{a}$ Atividade: Construindo tabela. Agora iremos organizar em uma tabela os dados da nossa pesquisa. Cada resposta anunciada oralmente pelo grupo, os alunos vão registrando na tabela. $3^{a}$ Atividade: Construindo gráfico e socializando resultados. Entreguei uma folha quadriculada para cada aluno construir o gráfico e barras referente à pesquisa, logo depois fizemos a socialização dos resultados através de questionamentos, registrando no caderno. Baseado no gráfico responda: Qual presente foi o mais votado? Qual presente foi o menos votado? Qual presente não teve votos?... (PA2).
\end{abstract}

Apesar de o excerto não ter um teor reflexivo, é relatado o desenvolvimento da atividade em suas diferentes etapas. Essa pesquisa envolveu outras classes da escola e teve uma fundamentação bem ligada aos interesses dos alunos - saber qual seria o 
DOI: http://dx.doi.org/10.33238/ReBECEM.2019.v.3.n.2.22607

presente escolhido por outras crianças. Apesar de não haver o registro das questões/dúvidas dos alunos, a professora relata os momentos de socialização de resultados e a construção por cada aluno de seu próprio gráfico.

Em relação a essa unidade a alfabetizadora relata que "Em grupo vivenciei diversos tipos de jogos, socializei com os demais tirando dúvidas, pois terei que aplicar um deles em sala de aula, como tarefa de casa" (PA2). E na avaliação da unidade frisa aspectos presentes nos materiais do programa:

Apresentar a Educação Estaística fornecendo ao professor elementos que permitam o planejamento de práticas pedagógicas que auxiliem a criança a reconhecer e produzir informações em diversas situações e diferentes configurações, ou seja, ler, interpretar e fazer uso das informações expressas, formular questões que gerem pesquisas e observações para coletar dados (PA2).

Ambos os trechos do portfólio da alfabetizadora apresentam a vivência de jogos, socialização com os pares e referências aos aspectos destacados nos textos dos cadernos de formação; o que consideramos como avanços na constituição da identidade profissional das docentes e na mobilização de conhecimentos pedagógicos.

Dando destaque ao ensino dessa temática, no item reflexão sobre a prática a PA3 afirma:

A aprendizagem da estatística desde as séries iniciais torna-se fator determinante para a construção desse ser humano crítico e atuante quando se depara com dados estatísticos, portanto é importante demonstrar que o ensino da estatística contribui para o desenvolvimento do cidadão que passa a analisar com mais criticidade e menos incredulidade dados de diversas pesquisas estatísticas. A educação deve ser apresentada como todos os conteúdos e suas disciplinas de forma lúdica, para que o aprendizado seja interessante e prazeroso, mediante esta realidade, o ensino de Estatística deve tratar de questões da realidade dos alunos, de forma a analisá-los na percepção de como as quantificações estão inseridas nos diversos cotidianos. É por meio da visualização da utilidade prática da Estatística, que os alunos perceberão sua importância no mundo real, ambiente do qual fazem parte (PA3).

Esta docente, assim como as colegas, demonstra ter aderido à perspectiva de ensino de Matemática apresentada pelo programa; passou a adotar a perspectiva do Pnaic. Para a PA o ensino de Estatística no ciclo de alfabetização oportuniza a formação critica dos alunos contribuindo para a formação de cidadãos atuantes na sociedade. Há a defesa da vinculação dos conhecimentos da Estística com a sua vinculação com a meio social, a realidade dos alunos. A docente argumenta sobre o ensino lúdico para que a aprendizagem dos alunos seja de forma interessante e prazerosa. 
DOI: http://dx.doi.org/10.33238/ReBECEM.2019.v.3.n.2.22607

$\mathrm{Na}$ tarefa de casa/escola, a alfabetizadora considera que essa unidade busca inserir a criança no universo da investigação, a partir de situações de interesse próprio, realizando coletas de dados e apresentando-os em gráficos e tabelas; para a docente:

Gráficos e tabelas, além de serem ferramentas para apresentação de dados,
são recursos para a elaboração de problematizações relativas a outros eixos
dos direitos de aprendizagem. Considera-se como fundamental na atitude
investigativa a preocupação em formular questões, elaborar hipóteses,
escolher amostras e instrumentos adequados para a resolução de problemas,
a coleta dos dados, a classificação e representação dos mesmos para uma
tomada de decisão. É nesse sentido que a pesquisa pode ser pensada como o
eixo principal da formação estatística dos alunos de todos os níveis de ensino.
Neste contexto, optei por apresentar três jogos diferentes para sala. O jogo da
senha, jogo das possibilidades e pintando o sete. Minha intenção apresentando
esses jogos é formular questões estatísticas, como por exemplo, quem fez mais
pontos em uma determinada rodada? Meninos ou meninas ganharam mais?
Qual o maior pontoado da sala? Etc (PA3).

Ao final de seu relato a PA salienta que sua intenção com os jogos era a de formular questões estatísticas com os alunos; ou seja, problematizar os conteúdos apresentados em cada jogo. Essa postura docente busca que as crianças observem situações de seu meio, de modo a levantar dúvidas ou problemas. A abordagem problematizadora possibilita incluir o aluno no processo de ensino de forma que as indagações promovam a reflexão. Cada pergunta deve estar ao alcance de ser respondida pelo aluno, seja de forma individual ou em grupo.

A PA4 na tarefa de casa/escola realizou a sequência didática "Animais de Estimação". A docente relata que:

No primeiro momento foi entregue aos alunos papel fazer uma pesquisa com alguns alunos da escola perguntando qual é seu bicho de estimação preferido. Após esta pesquisa, na sala de aula foi explorado o tema, e depois cada aluno falou do seu bicho de estimação. Foram selecionado os bichos escolhido pelos alunos da sala e tiveram bichos repetidos. Fiz uma tabela na lousa com os números dos votos dos alunos, em seguida resolvemos escrever sobre os bichos, cada um falou sobre o seu e depois desenhou. No momento seguinte resolvi fazer um gráfico sobre esses animais na lousa. Foi explorado coletivamente. Dentre eles foram feitas algumas perguntas para todos: -Quais são os animais mais votados? -Quais os menos votados? -Quais os que empataram? -E quais os preferidos pelos meninos? -E quais os preferidos pelas meninas? Após todo esse trabalho em sala, no pátio eu montei um a tabela e um gráfico no papel quadriculado avulso e distribui aos alunos para cada um fazer o seu, utilizando o seu próprio caderno como apoio e o resultado ficou assim: cachorro 7; gato 5; porco da índia 4; peixe 2; rato 1; tartaruga 1. Todos participaram de acordo com as suas expectativas, achei muito produtiva essa experiência, realizarei outras com novos temas no decorrer do minha trajetória de educadora (PA4).

A narrativa apresentada é sequenciada e bem organizada. É importante ressaltar no registro da professora que a atividade realizada não se restringiu a sala de aula, o que 
DOI: http://dx.doi.org/10.33238/ReBECEM.2019.v.3.n.2.22607

auxiliou a consolidar os conhecimentos; como a própria PA analisou foi uma atividade muito produtiva e os alunos participaram de acordo com suas expectativas.

Sobre atividades presentes no encontro, a alfabetizadora apresenta a reflexão em grupo sobre a probabilidade através de jogos e a socialização dessas reflexões com as demais cursistas.

Em relação a esse encontro, de Educação Estatística, a PA4 registra que "Observei e notei a importância do conteúdo da Educação Estatística, bem como a pesquisa de eixo estruturador, o valor dos dados obtidos pelos alunos durante a pesquisa realizada para construção de gráficos e tabelas" (PA4). Consideramos que a atividade de pesquisa nos anos iniciais possibilita a aquisição e elaboração de conhecimentos estatísticos, como também de outras áreas, fomentando a construção de novos conhecimentos, como também contribui para o desenvolvimento individual, ou mesmo no coletivo. Desde cedo é preciso cultivar nas crianças o espirito investigador, a pesquisa é um eixo estruturante da formação crítica, por meio da pesquisa e validação de saberes. Para isso é fundamental que o professor adote essa perspectiva em sua prática de ensino e de construção de conhecimento.

Barbosa (2014) enfatiza que ser preciso que os professores sejam incentivados a trabalharem com seus alunos os conteúdos da Estatística. "Por isso julgamos que assegurar discussões pedagógicas sobre o ensino dos conteúdos, principalmente dos menos explorados pelos professores, são fundamentais para que esses conteúdos sejam incorporados às práticas de sala de aula" (p. 70).

No item de reflexão e prática sobre o encontro a PA5 afirma ter considerado o tema Educação Estatística como fundamental.

\begin{abstract}
Unidade que considerei fundamental na atitude investigativa, a atenção em formular questões, elaborar hipótese, selecionar amostras e instrumentos adequados para a resolução de problemas, coletar dados; a classificação e representação dos mesmos para uma definição, é nesse sentido que a pesquisa pode ser pensada com eixo principal da formação estatística dos alunos de todos os níveis de ensino. O contexto de aprendizagem está presente a necessidade de desenvolver a enumeração de possibilidade, denominada combinatória, partindo de estratégias das próprias crianças é possível introduzir formas variadas de organizar os dados, tabelas, o raciocínio probabilístico que no ciclo de alfabetização não precisa ser sistematizado, pode ser iniciado a partir de situações lúdicas, buscando e desenvolvendo conceitos simples auxiliando ao aluno a reconhecer e produzir informações através das boas práticas pedagógicas (PA5).
\end{abstract}

As considerações da PA5 possuem estreita relação com as da sua colega, a PA4, frisando a atitude investigativa, a atenção necessária para a formulação de questões, elaboração de hipóteses, seleção de amostras e de instrumentos adequados para a 
DOI: http://dx.doi.org/10.33238/ReBECEM.2019.v.3.n.2.22607

investigação - resolução de problemas. No excerto há a menção a conceitos presentes nos matetriais de formação (coleta dados, classificação e representação, etc). Outra concepção adotada pela docente é a de que "a pesquisa pode ser pensada com eixo principal da formação estatística dos alunos de todos os níveis de ensino”. Eviencia-se no relato que a PA passou a adotar as concepções do Pnaic sobre o eixo de Tratamento da Informação para o ensino do tema; uma possível qualificação de seus conhecimentos para o ensino de Estatística. Um avanço nos seus conhecimentos pedagógicos do conteúdo matemático.

Para a tarefa de casa/escola, a alfabetizadora desenvolveu com sua turma de alunos a atividade "Animal doméstico de sua preferência".

\begin{abstract}
[...] no primeiro dia li Avestruz do autor Mário Prata (fiz adaptações). Depois eles responderam a pesquisa. No segundo dia organizei em 4 grupos de 4 alunos para que fossem as outras salas fazer a pesquisa (autonomia), do grupo ficou um aluno responsável para explicar as outras salas o que queriam e a prévia autorização do professor, enquanto os outros distribuíam as fichas com perguntas referentes a pesquisa, juntamente com eles fizemos a tabulação dos dados e exploramos os mesmos, organizamos as tabelas e posteriormente os gráficos. A atividade foi um sucesso onde pude observar que o envolvimento entre os grupos foi de grande importância, são esses momentos que percebemos os líderes, os mediadores, e notei que a maioria da sala são independentes (tem autonomia). Depois fizemos a interpretação dos gráficos, com questões como: qual a preferência das meninas, dos meninos. Dois alunos fizeram escolhas diferentes: Leão e cobra, questionei se havia a possibilidade de serem animais de estimação. Foi uma atividade muito produtiva, que podemos trabalhar vários conteúdos, é claro que sendo mediado. Contextualizei o conteúdo em outra disciplina realizando um relato da atividade na lousa. Aprendi que é primordial inserir na criança o censo de investigação, formular questões, pesquisar, coletar dados se comunicar, fornecendo a eles um planejamento voltado para sua realidade, torna-los criadores e idealizadores do que criaram (PA5).
\end{abstract}

O texto da alfabetizadora destaca a autonomia dos alunos durante a atividade e também as oportunidades das crianças contruírem tabelas e posteriormente gráficos. Para a PA a atividade desenvolvida foi muito produtiva e pode trabalhar vários conteúdos. Também ressalta que houve a contextualização com o conteúdo em outra disciplina - a multidisciplinaridade. Ao final ela afirma ter aprendido que é primordial inserir na criança o censo de investigação, formulando questões, pesquisando, coletando dados; fornecendo aos alunos um planejamento voltado para sua realidade, tornando-os criadores e idealizadores de sua aprendizagem. As perpectivas defendidas pela docente em seu relato estão extritamente ligadas às concepções do Pnaic e demonstram o alinhamento entre a PA e o programa de formação.

Em seu relatório da unidade a PA5 asseverou:

O encontro teve inicio com a dinâmica do copinho onde tinha os horários de chegada dos cursistas, após foi entregue os livros do acervo do Pnaic [...] Passou-se uma mensagem no data show com a leitura deleite Apostando com 
DOI: http://dx.doi.org/10.33238/ReBECEM.2019.v.3.n.2.22607

monstro; a orientadora explicou que esse livro pode abordadar vários eixos de matemática, refletindo sobre nossas práticas pedagógicas, precisamos buscar novas metodologias citado por ela, Antônio Nóvoa como referência metodológicas abordando a reflexão de mudanças de práticas. Foram tiradas algumas dúvidas sobre o encontro anterior, a respeito dos distratores e descritores, onde os cursistas participaram oralmente, a seguir estudamos variáveis qualitativas contínuas e discretas, explicado no data show, o estudo foi aprofundado com o estudo do caderno e a leitura dos direitos de aprendizagem, que teve como foco o estudo da Estatística, seu papel em nossos conteúdos. A orientadora aprofundou refletindo e fazendo-nos refletir que, precisamos melhorar nossas práticas e contextualizar nossos conteúdos. Retornamos com a classificação e categorização de Verônica Gitirana mostrando no cronograma de alimentos, é preciso trabalhar com as crianças práticas de classificação; e estudar dados e classificar uma das dificuldades dos alunos é definir um critério para a criação das categorias, realizamos em grupo o jogo de classificação dos brinquedos, depois no pátio organizamos o seminário e dividimos as unidades em grupos. Ao retornarmos do almoço foi feita a leitura deleite "Fugindo das garras do gato" passado no Power point, fizemos o estudo reflexivo do ensino de combinatória no ciclo de alfabetização, essa análise possibilitou através do jogos vividos em sala, como cara ou coroa, pintando o sete, corrida de piões de rios, jogos da sena e outros. Socializamos o que nos possibilitou sarnarmos as dúvidas e escolher um jogo para aplicar com tarefa de casa (PA5).

Apesar de seu teor descritvo, trazemos este registro do portfólio da PA5 onde podemos verificar de forma sintética como foi realizado esse encontro. Mesmo não apresentando nuances reflexivos, a professora menciona que a orientadora de estudos buscou que as cursistas estivessem refletindo sobre a prática e que o encontro envolveu diferentes conteúdos ligados à Estatística.

Destacamos que as reflexões das alfabetizadoras envolvem em sua maior parte reflexões e aspectos ligados ao conhecimento pedagógico do conteúco e em alguns momentos notamos nuances do conhecimento pedagógico geral. Em momento algum percebemos avanços nos conhecimentos sobre o conteúdo, mesmo no caderno de formação havendo incursões ao conhecimento do conteúdo, no registro das PAs não há registros dessa categoria.

Voltamos a enfatizar que os professores:

[...] não podem, simplesmente, ter uma compreensão intuitiva ou pessoal de um conceito, princípio ou teoria particular. Ao melhor, para se promover a compreensão, eles mesmos devem entender os meios de representar os conceitos para os alunos. Eles devem ter conhecimento sobre as maneiras de transformar o conteúdo com o objetivo de ensinar. (...) que inclui uma compreensão pessoal do conteúdo, assim como o conhecimento das maneiras de passar essa compreensão, a fim de promover o desenvolvimento do conhecimento do conteúdo nas mentes dos alunos (WILSON; SHULMAN; RICHERT, 1987, p. 110).

Para isso, são necessários momentos de formação que permitam aos professores se despirem de suas inseguranças, que manifestem seu "não saber", que sejam voltados a uma prática de ensino de construção de conhecimento e não de reprodução de 


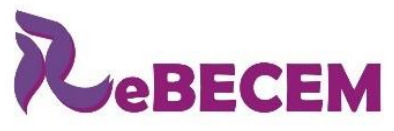

DOI: http://dx.doi.org/10.33238/ReBECEM.2019.v.3.n.2.22607

"inseguranças", pois como ensino Freire (1996) ninguém está apto a ensinar o que não sabe.

As atividades descritas pelas alfabetizadoras são exemplos voltados para a prática docente, por meio dos quais é possível abordar as ideias básicas e essenciais da Estatística em classes de alfabetização.

Destacamos que a proposta do Pnaic envolve a proposição de habilidades para serem desenvolvidas pelos alunos numa idade "certa", o que consideramos ser norteado por uma concepção de conhecimento curricular.

\section{Considerações finais}

Mesmo com limitações - seja no material de formação, seja no curso de formação - verificamos que o Pnaic apresentou uma proposta promissora de formação de professoras alfabetizadoras para o ensino de Estatística, nos porfólios são perceptíveis os indícios de avanços dos conhecimentos das professoras cursistas para o ensino da Estatística.

Ao analisarmos o material de formação e os registros das professoras em portfólios observamos que a proposta do Pnaic foi bem recebida pelas alfabetizadoras. No material são apresentados indícios de desenvolvimento profissional das docentes voltados aos conhecimentos para o ensino, principalmente ao conhecimento pedagógico da Estatística. O encontro de formação possibilitou situações ligadas aos princípios formativos destacados na proposta do curso de formação.

Destacasse práticas de ensino ligadas a pesquisa como eixo estruturador de ações pedagógicas e do conteúdo da Estatística. As atividades desenvolvidas pelas docentes se voltam para situações do cotidiano dos alunos que oportunizam aprender Estatística fazendo Estatística, pesquisando, organizando dados, representando-os em forma de gráficos, interpretando-os de forma crítica. Os jogos, outro ponto de destaque nos portfólios e no conteúdo do caderno de formação, também são possibilidades promissoras de desenvolvimento dessas habilidades.

É preciso ter a percepção que o conhecimento pedagógico do conteúdo é enriquecido com a interação dos diferentes tipos de conhecimentos e esse é o único conhecimento em que o professor pode estabelecer uma relação de protagonismo (MIZUKAMI, 2004). A base para o ensino é construída na prática do professor, no 


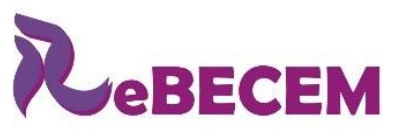

\section{Revista Brasileira de Educação em \\ Ciências e Educação Matemática \\ ISSN 2594-9179}

DOI: http://dx.doi.org/10.33238/ReBECEM.2019.v.3.n.2.22607

confronto com os desafios do cotidiano docente, na formação inicial e principalmente no exercício da atividade docente (SHULMAN, 1986).

Consideramos que o ensino da Estatística não pode se limitar a leitura e interpretação de dados; sua redução a aspectos técnicos, de maneira desconectada, em muitas vezes, em decorrência da inexperiência e desconforto que os professores possuem em relação a área. Os conhecimentos estatísticos não estão restritos à Matemática, mas se relacionam com assuntos de diversas disciplinas, reforçando seu caráter interdisciplinar. (BARBOSA, 2018)

Ademais, os professores precisam se preparar, se capacitar, se formar antes mesmo de iniciar sua atividade docente. A prática do dia a dia se bem percebida e bem vivida, deixa claro a necessidade de formação como um continuum (FREIRE, 1996). Investir na formação docente é investir na melhoria da qualidade da educação, pois o conhecimento, as crenças e as metas dos professores são elementos fundamentais na determinação do que fazem em sala de aula e de por que o fazem. (MIZUKAMI et al., 2010).

\section{Referências}

BALL, D.; THAMES, M. H.; PHELPS, G. Content knowledge for teaching: What makes it special? Journal of Teacher Education, New York, v. 59, n. 5, p. 389-407, nov. 2008.

BARBOSA, J. K. Tratamento da Informação e Prova Brasil de Matemática: ensino e avaliação. BoEM, Joinville, v. 2. n. 3, p. 51-71, ago./dez. 2014.

BARBOSA, J. K. Formação de professores alfabetizadores para o ensino e aprendizagem da estatística. REnCiMa, São Paulo, v. 9, n. 2, p. 107-126. 2018.

BATANERO, C. Estadística y didáctica de la matemática: Relaciones, problemas y aportaciones mutuas. In: PENALVA, C., TORREGROSA, G.; VALLS, J. (ed.). Aportaciones de la didáctica de la matemática a diferentes perfiles profesionales. 1. ed. Alicante (ES): Universidad de Alicante, 2002. p. 95-120.

BATANERO, C.; BURRILL, G.; READING, C. Overview: challenges for teaching statistics in school mathematics and preparing mathematics teachers. In: BATANERO, C.; BURRILL, G.; READING, C. (ed.). Teaching Statistics in School Mathematics - Challenges for Teaching and Teacher Education: A Joint ICMI/IASE Study. 1. ed. London: Springer, 2011. p. 407- 418.

BATANERO, C. e DIAZ, C. Training teachers to teach statistics: What can we learn from research? Statistique et Enseignement, Lyon. v. 1, n. 1, p. 5-20, abr. 2010.

BRASIL. MEC. Portaria $\mathbf{N}^{\mathbf{0}}$ 867/2012. Institui o Pacto Nacional pela Alfabetização na Idade Certa e as ações do Pacto e define suas diretrizes gerais. Brasília. 2012. Disponível em: http://pacto.mec.gov.br/images/pdf/2016/Portarias/PORTARIA_N_867_DE_4_DE_JULHO_D E_2012.pdf. Acesso em: 23 jul. 2017. 
DOI: http://dx.doi.org/10.33238/ReBECEM.2019.v.3.n.2.22607

BRASIL. MEC. Pacto Nacional pela Alfabetização na Idade Certa: Educação Estatística.

Brasília: MEC, SEB, 2014.

CAZORLA, I. O ensino de Estatística no Brasil. Sociedade Brasileira de Educação

Matemática - SBEM. [S.I.], 2004. Disponível em

http://www.sbem.com.br/gt_12/arquivos/cazorla.htm. Acesso em 20 out 2017.

CARZOLA, I.; SANTANA, E. R. dos S. Tratamento da informação para o ensino fundamental e médio. 1. ed. Itabuna: Via Litterarum, 2006.

CARZOLA, I. et al. Estatística para os anos iniciais do ensino fundamental. 1. ed. Brasília: Sociedade Brasileira de Educação Matemática, 2017.

CURI, E. Formação de Professores Polivantes: uma análise dos conhecimentos para ensinar Matemática e das crenças e atitudes que interferem na constituição desses conhecimentos. 2004. Tese (Doutorado em Educação Matemática: Currículo e Formação de Professores) - Pontifícia Universidade Católica de São Paulo, São Paulo, 2004.

D'AMBROSIO, U. Educação matemática: da teoria à prática. 1. ed. Campinas: Papirus, 1996.

FREIRE, P. A importância do ato de ler: em três artigos que se complementam. 23. ed. São Paulo. Autores associados: Cortez, 1989.

FREIRE, P. Pedagogia da autonomia: saberes necessários à prática educativa. 23. ed. São Paulo: Paz e Terra, 1996.

KATAOKA, V. Y. et al. A educação estatística no ensino fundamental II em Lavras, Minas Gerais, Brasil: avaliação e intervenção. Revista Latinoamericana de Investigación en Matemática Educativa, México, v. 14, n. 2, p.233-263, jul. 2011.

LOPES, C. A. E. O ensino da estatística e da probabilidade na educação básica e a formação dos professores. Cad. Cedes, Campinas, v. 28, n. 74, p. 57-73, jan./abr. 2008.

MIZUKAMI, M. da G. N. Aprendizagem da docência: algumas contribuições de L. S. Shulman. Educação, Santa Maria, RS. v. 29, n. 2, p. 17-32, jul./dez. 2004.

MIZUKAMI, M. da G. N.; REALI; A. M. de M. R. (org.). Formação de professores: práticas pedagógicas e escola. 1. ed. São Carlos: EdUFSCar, 2002.

MIZUKAMI, M. da G. N. et al. Escola e aprendizagem da docência: processos de investigação e formação. 2. ed. São Carlos: EdUFSCar, 2010.

SHULMAN, L. S. Those who understand: Knowledge growth in teaching. Educational Researcher, Washington, v. 15, n. 2, p. 4-14, fev. 1986.

SHULMAN, L. S. Knowledge and Teaching: foundations of the new reform. Harvard Educational Review, Massachusetts. v. 57, n. 1, p. 1-22, abr. 1987.

UNESCO. Os desafios do ensino de matemática na educação básica. Brasília: UNESCO; São Carlos: EdUFSCar, 2016. 
DOI: http://dx.doi.org/10.33238/ReBECEM.2019.v.3.n.2.22607

WILSON, S. M., SHULMAN, L. S. RICHERT, A. E. Different Ways of Knowing:

Representations of Knowledge in Teaching. In: CALDERHEAD, J. (ed.). Exploring Teachers' Thinking. 1. ed. Sussex, Londres. Inglaterra: Holt, Rinehart e Winston, 1987. p. 104-124.

Recebido em: 14 de junho de 2019.

Aceito em: 19 de agosto de 2019. 